\title{
Factors influencing the perceived credibility of diet-nutrition information web sites
}

Eun Hwa Jung ${ }^{\text {a, *, Kim Walsh-Childers }}{ }^{\mathrm{b}}$, Hyang-Sook Kim ${ }^{\mathrm{c}}$

a College of Communications, Pennsylvania State University, 115 Carnegie Building, University Park, PA 16802-5101, USA

b College of Journalism and Communications, University of Florida, 3044 Weimer, Gainesville, FL 32611, USA

c Department of Mass Communication and Communication Studies, Towson University, 8000 York Rd., Towson, MD 21252-0001, USA

* Corresponding author.

\section{Abstract}

This study investigated the factors that influence the perceived credibility of web sites providing diet and nutrition information. Undergirded by the dual-processing models (i.e., Elaboration Likelihood Model and Heuristic Systematic Model), an online experiment (N 575) was conducted to examine how perceptions of online diet and nutrition information credibility are influenced by source expertise cues and message accuracy; the effects of prior knowledge and interest in the information also were assessed. Results showed that message accuracy increased perceived credibility of the web site regardless of the level of source expertise. However, source expertise had an important effect on website credibility perceptions among those who exhibited low prior knowledge. Finally, message accuracy had a greater impact on web site credibility among those who were highly involved in the issue compared to those who were less involved. The findings increase our understanding of the factors that impact individuals' processing of online diet and nutrition information and suggest elements practitioners should consider including to create the most effective online sources for diet and nutrition information.

\section{Keywords}

Online diet and nutrition information

Source expertise

Message accuracy

Credibility

Information processing

Persuasion

\section{Introduction}

With the advent of new technology, people are now paying more attention to science-based health information (Thomm \& Bromme, 2012). In particular, many people are concerned about diet and nutrition information because the United States is in the midst of what the Centers for Disease Control have called an "obesity epidemic" (Centers for Disease Control, 2011). Because obesity can cause life-threatening diseases, it is regarded as a major problem, typically associated 
with poor dietary habits (Malik, Willett, \& Hu, 2013). Controlling one's dietary habits and caloric intake should be the first move to avoid weight gain and lower the risk of developing obesity-related diseases such as diabetes and cancer. However, Crow (2012) has suggested that one reason many Americans are overweight is that they do not understand what constitutes a healthy diet. Thus, people need access to appropriate diet and nutrition information, which could help diminish the obesity epidemic.

In today's society, the Internet plays a significant role in heath information seeking among the public. The Pew Internet and American Life Project survey revealed that, in 2013, 72\% of American Internet users had searched for health information online (Fox \& Duggan, 2013). These numbers suggest that the convenience of accessing online information supersedes visiting a doctor in terms of satisfying people's desire to obtain information about their health problems. Therefore, the Internet can help users gather health information by providing consumers with useful knowledge about health-related issues (Wang, Wang, Wang, Liang, \& Xu, 2012).

However, people are sometimes confused by the information they find online, simply because of the overwhelming volume of data the Internet provides (Goldberg \& Sliwa, 2011; Theodosiou \& Green, 2003). The volume of information, including often conflicting information, can cause people to wonder whether the information they find online is indeed correct. Consumers' perception of the credibility of online information plays a key role in determining which websites they find useful (Lim \& Van Der Heide, 2015). Previous studies have suggested that credibility significant influences users' perceptions of health-related messages and their behavioral responses to those messages (e.g., Harris, Sillence, \& Briggs, 2009; Hu \& Sundar, 2010). If health professionals and organizations hope to harness public use of online information as a tool in reducing the rates of overweight and obesity, they need to understand how individuals decide which online information to trust in making decisions about their diet. Although a few studies have investigated participation in online nutrition-related interventions (Colleran \& Lovelady, 2012; Robroek, Brouwer, Lindeboom, Oenema, \& Burdorf, 2010; Robroek, Lindeboom, \& Burdorf, 2012; Thorndike et al., 2012), the relationship of credibility with message features and source cues has not been investigated comprehensively (Hong, 2006). To help fill this gap in online health communication research, this study investigated the impact of two key factors that may influence how people determine the credibility of online health information. Specifically, the present study investigated diet/nutrition information credibility through the lens of the dual-processing models; the purpose was to determine how source expertise and message accuracy affect information credibility in online media platforms.

\section{Literature review}

To obtain diet and nutrition information, people can consult many sources, including individual counseling provided by health professionals, mass media, health education materials, and others (Charlton, Brewitt, \& Bourne, 2004). Although interpersonal communication - mostly with health professionals, including dietitians, doctors, and nurses - is considered a reliable source to obtain health information (American Dietetic Association, 2008), there are important limitations on delivering health information to people through interpersonal contact. First, to receive information this way, consumers must take the time to meet with a health professional and must pay for the medical services they receive; this, in turn, will make many consumers unwilling to seek health professionals' advice on diet. For example, qualified professionals have treated fewer 
than half of obese patients in spite of the tens of billions annually spent on weight loss products (Ayoob, Duyff, \& Quagliani, 2002). Instead, people would rather rely on health information available online (Bass et al., 2006; Buntin, Burke, Hoaglin, \& Blumenthal, 2011). Indeed, McConnon, Kirk, and Ransley (2009) found that individuals were satisfied with using web sites for information about weight loss.

\section{Why is credibility important for online diet-nutrition information?}

Since the Internet era emerged, people with health concerns have been searching online for relevant information (Fox \& Jones, 2009). In particular, surveys have shown that one of the most common health-related search topics is diet and nutrition information; in a 2006 survey, 49\% of Internet users reported having looked online for such information (Fox, 2006). Wilson (2007) suggested that when people seek diet and nutrition information, they assess source and message factors to determine its trustworthiness. As a consequence, health information providers must ensure that they design messages carefully to address consumers' needs for effective diet and nutrition information (Wei, Rickard, \& Brown, 2015). Most of all, messages provided by the media should be considered carefully because the content they provide can have a significant impact on public perceptions and behavior (Tudoran, Olsen, \& Dopico, 2009; Wilson, 2007).

Despite the public's desire for diet and health information, the dietary information consumers find in an information-overloaded environment is frequently confusing (Goldberg \& Sliwa, 2011; Spiteri Cornish \& Moraes, 2015). In particular, the largely unregulated online environment leaves many people doubt the credibility of online health information (Fahy, Hardikar, Fox, \& Mackay, 2014). Consumers often find it difficult to determine the veracity of online health information (Modave, Shokar, Peñaranda, \& Nguyen, 2014).

Another reason credibility is so vital to providing consumers with high-quality diet-nutrition information online is that people can easily and quickly access inaccurate health information through a variety of peer-to-peer communication venues. For example, inaccurate advice provided by unqualified individuals can be exchanged in chat rooms, especially since most chat rooms allow users to remain anonymous (Flanagin \& Metzger, 2003; Neuhauser \& Kreps, 2003). This problem is likely to happen in online health message boards as well. Email exchanges also frequently spread false information about health issues or products (Baker, Wagner, Singer, \& Bundorf, 2003). Additionally, social media may provide misleading health information because this information, usually generated by peers or laypersons, may be inaccurate and/or lack source credibility (Rutsaert et al., 2013; Vance, Howe, \& Dellavalle, 2009). For example, Tsai, Tsai, ZengTreitler, and Liang (2007) found that $54 \%$ of health information on social networking sites contained incomplete and inaccurate content. Such misinformation on the Internet causes users to become confused and to change their perceptions and behaviors, which can be harmful (Spiteri Cornish \& Moraes, 2015).

\section{Theoretical mechanisms of assessing information online}

While the previous section explained the importance of credibility for online diet-nutrition information, a critical question remains unanswered: which aspects of online information contribute to consumers' credibility perceptions? Dual-process models in persuasion research the Elaboration Likelihood Model (ELM) (Petty \& Cacioppo, 1986; Petty \& Wegener, 1999) and the Heuristic - Systematic Model (HSM) (Chaiken, 1980; Chen \& Chaiken, 1999; Eagly \& Chaiken, 1993), 
argue that when people process messages containing cues, such as a long message, high-quality arguments, and credible and attractive sources, they tend to evaluate the message based on the cursory-judgment rule. As a result, such heuristic cues create favorable attitudes toward the messages and thereby induce persuasive effects. However, message recipients' motivational situation e whether they are highly interested in or knowledgeable about the message - can shift processing from the heuristic mode to systematic processing. When recipients engage in more careful consideration of the message through systematic information processing, both the quality and the source of the message will play a critical role in amplifying or suppressing the persuasive effects (Hallahan, 2000; Kruglanski et al., 2006).

\section{The effects of source expertise and message accuracy on diet-nutrition information processing online}

In assessing diet-nutrition information on the Internet, people want to confirm that the information comes from an expert source. Previous research has demonstrated that higher source credibility generates more positive attitudes toward a persuasive message (Metzger, 2007; Reinhard \& Sporer, 2010). Expertise (e.g., Center for Disease Control and Prevention, National Institute of Health) is one of the best-known source cues in dual-processing research. For example, Eastin (2001) proposed that knowledge of content and source expertise have a strong influence on users' perceptions of the credibility of health websites, and in particular, source expertise had a main effect on perceived credibility of health information. Walther, Wang, and Loh (2004), using advertisements on health websites, also demonstrated that source expertise is a significant factor in perceptions of website credibility. Hu and Sundar (2010) suggested that source cues related to expertise (i.e., professional vs. layperson) on a web site play an important role in individuals' perception of credibility. Furthermore, they found individuals had more behavioral intention (i.e., the degree to which individuals adopt the advice offered in the message) toward health information sourced from a website than from a bulletin board, a blog, a personal home page, and the Internet. Based on the previous findings, the current study employed expertise as the main source cue that would trigger source credibility heuristics and thereby enhance the perceived credibility of the information.

Meanwhile, ELM's operationalization of argument quality needs to be refined, clarifying its role as the primary cause for one's message processing. Early works by Petty and Cacioppo (e.g., Petty \& Cacioppo, 1984) do not make clear conceptual distinctions between arguments and cues in messages. The argument manipulations used in previous studies by Petty and Cacioppo and their colleagues relied heavily on the number of source cues. As Eagly and Chaiken (1993) argued, it seemed that Petty and Cacioppo (1984) encountered self-contradiction, thereby concluding that "endorser attractiveness had functioned as a peripheral cue when personal relevance was low, but as a persuasive argument when personal relevance was high. In the latter condition, attractiveness provided persuasive visual testimony as to the effectiveness of a beauty product" (Eagly \& Chaiken, 1993, p. 320).

Instead of operationalizing argument quality based on the number of cues available in a message, as critiqued above, it might be more useful to operationalize the level of message clarity in terms of message accuracy. Levine and McCornack (2001) proposed the idea that the probing process could play the role of a heuristic cue. Probed (i.e., accurate) messages are regarded as more "truthful" than un-probed messages, so they are likely to influence individuals' behaviors, as they are generally perceived to be more "honest" (Levine \& McCornack, 2001). Interestingly, people processed the message with the high level of truthfulness heuristically only in the low involvement 
condition (Levine \& McCornack, 2001).

Some research in dual-processing models has made conceptual connections between message accuracy and the level of deceptiveness. Depending on the level of deceptiveness and truthfulness, individuals will process messages using different cognitive paths - either systematic or heuristic. For example, Reinhard and Sporer (2010) explored how different source cues and message manipulations influenced perceived credibility. In particular, they manipulated content information to vary the level of deceptiveness and message accuracy. The study showed that for audiences with low involvement, only source cues (i.e., source attractiveness and trustworthiness) had a significant impact on perceived credibility. On the other hand, for those with high involvement, message manipulation (i.e., truthful vs. deceptive) significantly influenced participants' perceived credibility. Therefore, the study supported the notion that systematic processing is captured in message accuracy while heuristic processing is captured by source cues. Despite a slightly different focus of source cue conceptualization from the present study (i.e., expertise), this previous work showed that the source cue and the level of message accuracy (i.e., how correctly the message was presented) both come into play when message recipients form credibility perceptions (Reinhard \& Sporer, 2010).

Taken together, when it comes to diet and nutrition information online, we still do not fully understand how source cues and message accuracy interact with each other to influence consumers' cognitive evaluations of health information. Drawing upon dual process models (Chaiken, 1980; Petty \& Cacioppo, 1986), the present study argues that, first, when an expert cue is available in online diet and nutrition information, individuals will process the information more readily, in turn producing a greater level of perceived credibility. On the other hand, when participants are motivated to scrutinize the information more carefully by assessing message accuracy, systematic processing will occur, eventually generating a greater level of perceived credibility as a result of accuracy at a high level than a low one.

H1. Diet-nutrition information with an expert source cue will produce a greater level of perceived credibility than one without such a cue.

H2. Diet-nutrition information with a higher level of message accuracy will produce a greater level of perceived credibility than will a lower level of message accuracy.

Often, two routes of cognitive processing e heuristic and systematic e occur simultaneously depending on availability of various cues. For instance, recipients exposed to an inaccurate message that also contains cues to high source expertise process the message quality systematically while responding to source expertise heuristically. Such a disconnection between source expertise and message quality likely would lead to lower evaluation of the message and less persuasive impact (i.e., attenuation hypothesis of the HSM, Eagly \& Chaiken, 1993). On the other hand, systematic processing of an accurate message, along with a heuristic cue that suggests high source expertise, will consistently signal the high message quality of message, leading to more favorable message evaluations; the persuasive effect of message quality should be greater when source expertise is high, in comparison to messages that contain no source expertise cue (i.e., additivity hypothesis of the HSM, Eagly \& Chaiken, 1993; see Chaiken, Liberman, \& Eagly, 1989 for a more detailed comparison of ELM and HSM). 
However, few studies have demonstrated this co-occurrence of dual modes of processing for online information (e.g., Lee \& Sundar, 2013). In one study of perceptions of Twitter content, people found the information credible when it was retweeted by a health expert after another health expert originally had tweeted the information. This is an example of the additivity hypothesis; people's heuristic processing eventually led to systematic processing, which did validate the credibility of information more than when the original mention was tweeted by an ordinary Tweeter user. On the other hand, when a health expert simply retweeted a health-related mention originally tweeted by a non-health expert, people tended to discount the credibility of information. The attenuation hypothesis is evidenced in this case because people could have expected credible information from the retweeted message by an expert source, but found that the original source of the retweeted message (i.e., source of tweet) was non-expert, which significantly discounted the credibility of the message retweeted (Lee \& Sundar, 2013). However, the health information tested in Lee and Sundar's study (2013) was somewhat controversial to reach the conclusion in that the ways of losing weight described in the tested messages were not scientifically verified. Thus, it seems plausible that people perceive online diet and nutrition information as more credible when the information not only includes a cue signaling high source expertise but also high information accuracy.

H3. There will be a significant interaction effect between source expertise and message accuracy in the diet-nutrition information.

\section{Moderating effects on online diet-nutrition information processing}

Eagly and Chaiken (1993) suggested that prior knowledge about a topic is a critical factor influencing information processing with heuristic cues. They found that knowledge level plays an important role in individuals' ability to assess message credibility. Individuals with high levels of knowledge about the message have greater ability to process information or to interpret the message critically. Consistent with this finding, Eastin (2001) found that knowledge about a message had a significant influence on perceived information credibility in the context of online health communication. Specifically, he concluded that a high level of knowledge led to greater perceived credibility of online health information. Kerstetter and Cho (2004) also demonstrated that prior knowledge is an essential factor to explain information search behavior in the tourism context. More specifically, they found that prior knowledge was positively correlated with the perceived credibility of sources in search information. Further, Grunert et al. (2012) argued that nutrition knowledge has important effects on consumers' processing of information in decisionmaking about food choices. These previous studies indicate that prior knowledge about message content can have a significant impact on online information processing. Because individuals vary in their levels of knowledge concerning diet and nutrition, the following hypothesis was investigated:

H4. : Knowledge level will moderate the effects of source expertise and message accuracy on perceived credibility.

In addition to having prior knowledge about the message topic, issue involvement is relevant to the present study as well. Issue involvement is generally defined as the degree to which individuals find an issue relevant (Petty \& Cacioppo, 1990). Reinhard and Sporer (2010) found that involvement played an important role in information processing to determine credibility. In particular, the ELM explains that a high level of involvement leads to systematic processing, while 
heuristic processing occurs at lower levels of involvement (Petty \& Cacioppo, 1990). Given this, prior studies employing ELM have observed different information processing effects on persuasion under high and low involvement conditions. For example, Chaiken (1980) explored the effects of message argument (i.e., the number of arguments: six vs. two) and source (i.e., likable vs. unlikable communicator) on persuasion. The study found that message recipients engaged in systematic information processing (i.e., message-based cognition) under high involvement conditions, whereas message recipients employed a heuristic processing strategy (i.e., simple decision rules) under low involvement conditions. Consistent with these findings, the results of Petty, Cacioppo and Goldman's (1981) examination of the effects of argument quality (i.e., strong or weak arguments) on persuasion suggest that argument quality increases persuasion under high involvement conditions and source credibility influences persuasion under low involvement conditions.

In the context of online health communication, Neuhauser and Kreps (2003) suggested that issue involvement is strongly related to individuals' perceptions and behaviors related to their health. Street and Piziak (2001) stated that users who are highly involved in health issues tend to pay more attention to related health messages than those who are less involved in the issue. Consistent with this approach, the present study predicted that the level of issue involvement would moderate the effects of message accuracy and source expertise on perceived credibility of diet and nutrition information. This argument leads to the following hypothesis:

H5. Issue involvement will moderate the effects of source expertise and message accuracy on perceived credibility.

\section{Method}

We investigated the effect of source expertise and message accuracy on perceived web site credibility by employing a $2 \times 2$ between-participants experimental design. A pretest was performed to verify the manipulations of source and message variations in the web site stimuli. Based on the results from the pretest, the main study was carried out to test the hypotheses.

\section{Webpage stimuli}

Four versions of the webpage stimulus were created, with variations in source expertise and message accuracy. The webpage included messages about diet and nutrition and the recent trend toward eating healthier food. According to the ADA's 2008 survey, most people were interested in their intake of whole grain foods and believed that whole grain foods are healthier than refined grain foods (e.g., white bread). In addition, previous studies have shown that whole grain foods not only provide health benefits, especially improving diet and nutrition, but also reduce the risk of diseases such as cancer (e.g., Jacobs, Pereira, Slavin, \& Marquart, 2000; McIntosh, Noakes, Royle, \& Foster, 2003). This implies that whole grain foods have attracted public attention for their nutritional attributes. Therefore, the present study used an article about whole grain intake based on a press release provided by the ADA.

Two of the stimulus webpages provided an accurate message, while the other two included information that had been edited to be inaccurate (See Appendix I for the manipulation details). For example, while the accurate message contained information about the importance of whole grains in individuals' diets, 
the inaccurate message said that whole grains are not especially important. In addition, the two webpage stimuli were presented as coming from the CDC web site (i.e., high level of source expertise) and a personal blog (i.e., low level of source expertise). Table 1 shows the information about each stimulus.

Pretest: Pre-manipulation check. Thirty-three students participated in the pretest and were compensated for their time with extra credit. Students were recruited from undergraduate classes at a large Southeastern university. The participants were asked to rate the level of source expertise and message accuracy of each webpage stimulus by using 7-point Likert scales ranging from 1 (Strongly disagree) to 7 (Strongly agree).

Five incomplete responses were excluded, leaving 28 pre-test responses to be analyzed. T-tests examined variations in perceived level of source expertise and message accuracy. There were significant differences in terms of source expertise $(\mathrm{t}=4.69, \mathrm{p}<.001)$ and message accuracy $(\mathrm{t}=3.77$, $p<.001)$. Specifically, participants perceived that the CDC webpage $(M=5.28, S D=1.13)$ had more expertise than the personal blog $(M=3.48, S D=.89)$, and the original accurate message $(M=4.94$, $S D=1.18)$ was more accurate than the rewritten inaccurate message $(M=3.17, S D=1.27)$. These findings confirmed that there were significant differences in the four versions of the webpage stimuli.

\section{Main study: sample selection}

For the main study, 580 students were recruited from large classes in the communication college at a large Southeastern university. Five incomplete responses were dropped, so that the final valid number for the sample was 575 . Female participants $(66.8 \%, \mathrm{n}=386)$ outnumbered male participants $(33.2 \%$, $\mathrm{n}=191)$. The ages of participants ranged from 17 to 29 , with a mean age of 19.91 years old and a median age of 20 years old $(30.8 \%, \mathrm{n}=177)$. Of all participants, 96 were freshmen $(16.7 \%), 194$ were sophomores (33.7\%), 197 were juniors $(34.3 \%)$, and 87 were seniors $(15.1 \%)$. In terms of ethnic background, more than half of the participants $(57.4 \%, \mathrm{n}=330)$ were non-Hispanic whites, 79 were Hispanic (13.7\%), 39 were African American (6.8\%), 32 were Asian (5.6\%), and 95 were from other ethnic groups $(16.5 \%)$.

Table 1

Web page versions.

\begin{tabular}{|c|c|c|c|}
\hline Versions & Conditions & & Websites \\
\hline 1 & High source expertise & High message accuracy & Centers for Disease Control (http://www.cdc.gov) \\
\hline 2 & & Low message accuracy & \\
\hline 3 & Low source expertise & High message accuracy & “Susan's Nutrition” Weblog (http://vegan.typepad.com) \\
\hline 4 & & Low message accuracy & \\
\hline
\end{tabular}

To investigate how subjects use media, especially the Internet, the online experimental instrument included questions about participants' media use for diet and nutrition information. Sixty (10\%) participants reported that they had visited the CDC web site, while 498 had not (86.61\%). None of the subjects reported having visited the personal blog $(45.91 \%, \mathrm{n}=264)$.

Participants were also asked about what kind of media they usually use to get diet and nutrition information. The majority of subjects reported using the Internet $(40.9 \%, \mathrm{n}=235)$ to get diet and nutrition information, followed by other people, such as parents and friends $(20.9 \%, \mathrm{n}=120)$, health professionals $(18.4 \%, \mathrm{n}=106)$, newspapers/magazines $(12.5 \%, \mathrm{n}=72)$, television/radio $(6.1 \%, \mathrm{n}=35)$, and other sources $(1.2 \%, \mathrm{n}=7)$. This finding indicates that the Internet is the medium most frequently used for diet and nutrition information. In terms of frequency of Internet use for diet and nutrition information, most subjects had used the Internet once or twice 
to search for diet and nutrition information $(45.9 \%, \mathrm{n}=264)$, followed by once a month $(21.4 \%, \mathrm{n}=123)$, once a week $(7.3 \%, \mathrm{n}=42)$, and daily $(2.6 \%, \mathrm{n}=15) ; 131$ participants had never sought diet and nutrition information online $(22.8 \%)$.

\section{Conceptual measures}

Perceived source expertise was defined as the level of credibility attributed to the sponsoring web site, an indication of whether the respondent believed the web site sponsor to be a qualified expert (Flanagin \& Metzger, 2003). The questions assessing source expertise included "This site sponsor is credible," "This site sponsor has high integrity," "This site sponsor's reputation is positive," "This site sponsor is successful," and "This site sponsor is trustworthy." All items were measured using a 7-point Likert scale ranging from 1 (strongly disagree) to 7 (strongly agree). The reliability of the scale was $\alpha=.95$.

Message accuracy was concerned with whether or not the message on a web site was seen as accurate and was measured using a single item: "This message is accurate" (Bucy, 2003; Flanagin \& Metzger, 2003). This item was rated on a 7-point rating scale with 1 meaning "Totally inaccurate" and 7 meaning "Totally accurate."

Level of prior knowledge was defined as whether participants knew facts about whole grain foods or not. The items consisted of four statements that were taken from the press release provided by the ADA: "Whole grains are better for your health than refined grains" (true) "Eating whole grains does not increase fiber intake" (false), "The benefits of consuming whole grains include a reduced risk of stroke, type 2 diabetes, and heart disease" (true), "Whole grain intake helps to control weight gain and prevent obesity," (true), and "Nutrition provided by whole grains has no effect on health" (false). Participants selected "True," "False," or "I do not know" for each statement. The total score for each participant's prior knowledge about the health topic was calculated by summing up each person's score, where the correct answer was 1 and the incorrect answer or "don't know" was 0 . For the final analyses, a median split was performed to create two groups, one with low prior knowledge ( $M$ $=1.8, S D=.43)$ and one with high prior knowledge $(M=3.14, S D=.34)$.

Issue involvement was defined as the degree to which the subject of whole grain foods is of concern, relevance, and importance to participants (Petty \& Cacioppo, 1990). To measure this variable, three statements were employed: "I am concerned about including whole grain foods in my diet," "Information about whole grain foods is very relevant to me," and "Understanding the value of whole grain foods is important to me" $(\alpha=.85)$. Agreement with each item was rated on a 7-point rating scale ranging from 1 (Strongly disagree) to 7(Strongly agree). A median split was performed to produce a low issue-involvement group $(M=3.61, S D=.96)$ and a high issue-involvement group $(M=5.8, S D=.7)$ for the final analyses.

Web site credibility was defined as the extent to which the web site was perceived to demonstrate fairness (e.g., "This site provides information that is neutral," "This site provides information that is balanced."), depth (e.g., "This site provides in-depth information," "This site is comprehensive."), goodwill (e.g., "This site has my interests at heart," "This site is concerned about its visitors."), and trustworthiness (e.g., "This site is ethical," "This site is trustworthy.") (Gaziano \& McGrath, 1986; Hong, 2006; Hovland \& Weiss, $1951)$. All items were rated on a 7-point rating scale ( $1=$ "Strongly disagree" and $7=$ "strongly agree") $(\alpha=.88)$.

\section{Procedure}

An online experiment was conducted using the Qualtrics online survey system. Four versions of the questionnaire were used, and each participant was randomly assigned to one of the four experimental conditions. Participants completed the questionnaire after viewing a webpage asking them to rate the web site's credibility; the questionnaire included manipulation check items measuring perceptions of source expertise and message accuracy as well as knowledge about whole grains, issue involvement, Internet experience, and 
demographic variables.

\section{Results}

\section{Manipulation check}

To assess the success of the manipulations for accuracy and source expertise, we used t-tests to determine whether participants who read different versions of the message differed in their ratings of source expertise and message accuracy. The $\mathrm{t}$-test findings revealed significant differences in ratings of source expertise $(\mathrm{t}=6.95, p<.001)$ and message accuracy $(\mathrm{t}=14.73, p<.001)$. Consistent with the results of the pretest, participants perceived the CDC $(M$ $=4.92, S D=.99)$ as being more expert than the personal blog $(M=4.35, S D=.93)$. Regarding message accuracy, participants perceived that the original accurate message $(M=5.25, S D=.92)$ was more accurate than the rewritten inaccurate message $(M=3.92, S D=1.25)$.

\section{Hypotheses testing}

Three sets of factorial ANOVAs were performed to test the hypotheses. First of all, a 2 (source expertise) X 2 (message accuracy) ANOVA was conducted to examine Hypotheses 1, 2, and 3. As shown in Table 2, a factorial ANOVA with the source expertise cue and message accuracy manipulations revealed a main effect for message accuracy $\left[F(1,571)=128.28, p<.001\right.$, partial $\left.\eta^{2} .=18\right]$, which supported the second hypothesis of the present study. Accurate diet-nutrition information produced higher ratings of web site credibility $(M=4.44, S D=.77)$ than did inaccurate information $(M=3.68, S D=.88)$. However, the source cue $\left[F(1,571)=.10, p>.05\right.$, partial $\left.\eta^{2}=00\right]$ did not produce any effect on overall perceived web site credibility among the participants. In addition, there was no significant interaction effect $[F(1,571)=$ $2.83, p>.05$, partial $\left.\eta^{2}=.01\right]$ of source expertise and message accuracy. Therefore, Hypotheses 1 and 3 were not supported.

Second, a 2 (source expertise) X 2 (message accuracy) X 2 (knowledge level) ANOVA was carried out to assess the fourth hypothesis. Controlling for prior nutrition knowledge level, not only was the main effect for message accuracy significant $\left[F(1,567)=96.65, p<.001\right.$, partial $\left.\eta^{2}=.15\right]$, but there also was a significant interaction effect between source expertise and message accuracy $[F(1,567)=5.26, p<.05$, partial $\left.\eta^{2}=.01\right]$ (Table 3). Specifically, the information with the source expert (i.e., CDC web site) $(M=$ $3.78, S D=.88)$ produced a greater level of perceived web site credibility than that without the source expert cue (i.e., the personal blog) $(M=3.61, S D=.87)$ in the inaccurate message condition. On the other hand, participants perceived the web site without source expert cue $(M=4.54, S D=.76)$ as more credible than the web site with expert cue $(M=4.36, S D=.78)$ when the message was accurate (see Fig. 1). (see Table4).

Furthermore, the analysis also revealed a marginally significant three-way interaction effect among source expertise, message accuracy, and prior knowledge level $\left[F(1,567)=3.84, p=.05\right.$, partial $\left.\eta^{2}=.01\right]$. The two-way interaction effect between source expertise and message accuracy was valid only for participants with low prior knowledge about whole grain intake (see Fig. 2). Specifically, for those with low prior knowledge, accurate information without expert cue $(M=4.64, S D=.67)$ was rated more credible than accurate information with expert cue $(M=4.25, S D=.91)$, while inaccurate information with expert source cue $(M=3.91, S D=.81)$ was rated more credible than inaccurate information without expert cue $(M=$ $3.64, S D=.99)$. When participants were more knowledgeable about diet and nutrition, then expertise did not influence their message processing and thus had no effect on perceived web site credibility, whereas message accuracy did; the accurate message $(M=4.47, S D=.77)$ was perceived as more credible than the inaccurate message $(M=3.62, S D=.87)$. Therefore, Hypothesis 4 was partially supported.

Lastly, a 2 (source expertise) X 2 (message accuracy) X 2 (issue involvement) ANOVA was employed to 
test the fifth hypothesis. The analysis produced main effects for message accuracy $[F(1,567)=128.03$, $p<.001$, partial $\left.\eta^{2}=.18\right]$ and level of involvement $\left[F(1,567)=5.97, p<.05\right.$, partial $\left.\eta^{2}=.01\right]$. The accurate information produced higher perceived credibility ratings $(M=4.44, S D=.77)$ than did the inaccurate information $(M=3.68, S D=.88)$, which supported the second hypothesis. In addition, high issue involvement resulted in greater perceived credibility $(M=4.15, S D=.96)$ than did low involvement $(M=4.00, S D=.85)$.

This data also revealed a significant interaction between message accuracy and level of involvement $[F$ $(1,567)=6.51, p<.05$, partial $\left.\eta^{2}=.01\right]$. Participants' issue involvement altered their perceived credibility level in the accurate message condition such that, when the information was accurate, participants with high issue involvement reported greater perceived website credibility than participants $(M=4.62, S D=$ $.75)$ with low issue involvement reported greater perceived website credibility than participants $(M=4.62$, $S D=.75)$ with low issue involvement $(M=4.26, S D=.76)$; however, there was no difference in perceived credibility in the inaccurate message condition regardless of participants' issue involvement (see Fig. 3). Therefore, Hypothesis 5 was partially supported

In summary, the results of the present study show that 1) message accuracy produced strong main effects on web site credibility without reference to the level of source expertise, 2) significant interaction effects of source expertise and message accuracy existed for those with low prior knowledge, and 3) the significant interaction effect between message accuracy and issue involvement showed that message accuracy has a greater impact on web site credibility for those who are highly involved in the issue compared to those who are less involved.

\section{Discussion}

This study was designed to help us understand key influences on how people perceive the credibility of web sites that provide diet and nutrition information. In particular, the study examined two major variables (i.e., message accuracy and source expertise) that should be related to perceived web site credibility, based on dual-processing models. The study produced some noteworthy findings.

First, message accuracy yielded strong main effects on web site credibility without reference to the level of source expertise. Specifically, participants exposed to the original accurate message perceived the web site to be more credible than those who were exposed to the inaccurate message, regardless of whether the web site was produced by the CDC or someone's personal blog. This result supports a previous study by Kunst, Groot, Latthe, Latthe, and Khan (2002), which argued that message accuracy is an important variable in evaluating web site credibility. However, this finding needs to be examined in relation to other factors pertaining to information assessment. A significant three-way interaction effect among source expertise, message accuracy and knowledge level, although marginal, suggests that low-knowledge participants exposed to the inaccurate message paid more attention to source expertise than did those exposed to the accurate message. However, when the message delivered accurate information, source expertise would not matter much. This is also true of those who were knowledgeable about the message; perceived credibility of accurate web site information was higher for those who were highly involved with the subject of whole grain intake (see Figs. 1 and 2). 


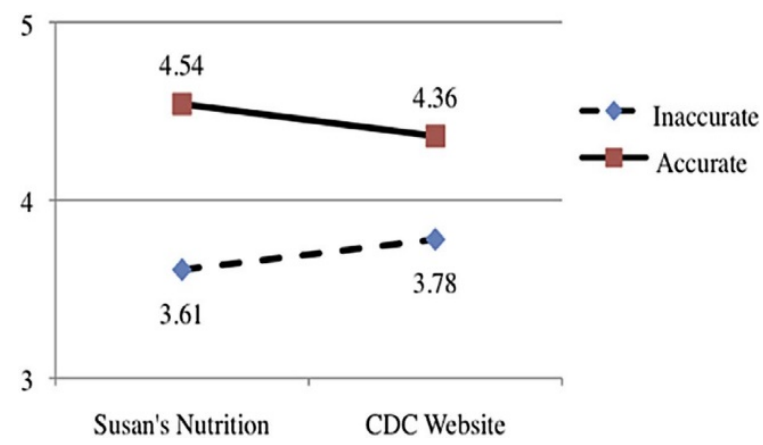

Fig. 1. Interaction effect between source expertise and message accuracy on web site credibility.
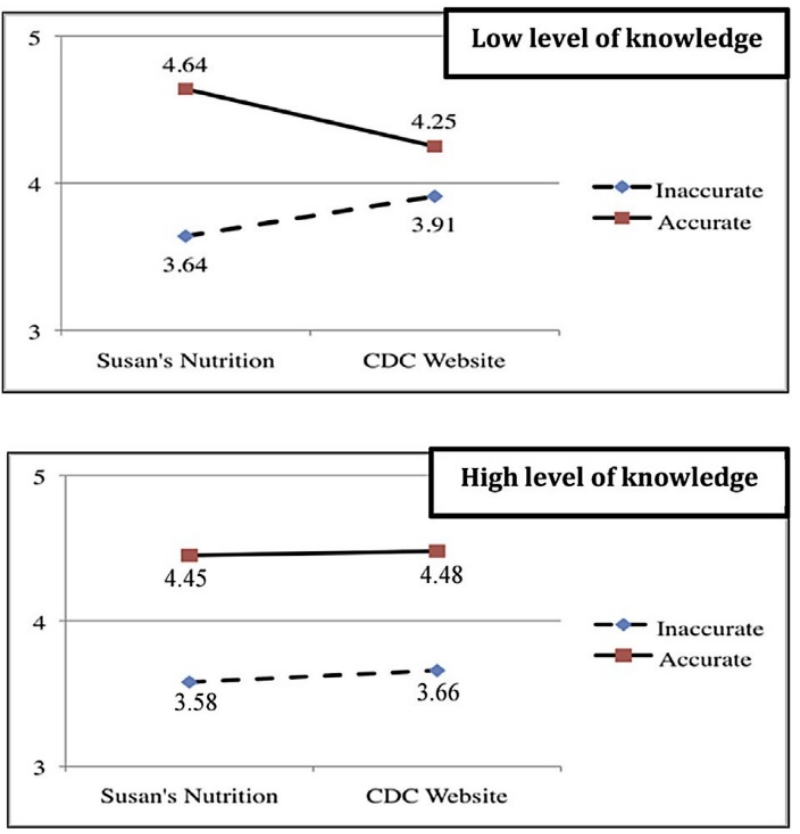

Fig. 2. Three-way interaction of source expertise $\mathrm{x}$ message accuracy $\mathrm{x}$ knowledge on web site credibility

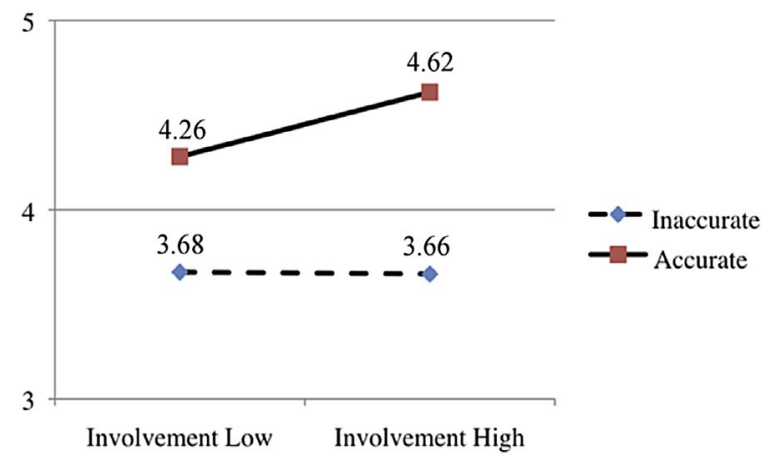

Fig. 3. Interaction effect between message accuracy and issue involvement on web site credibility. 
Table 2

Two-way ANOVA for web site credibility.

\begin{tabular}{|c|c|c|c|c|c|c|}
\hline & Type III sum of squares & df & Mean square & $\mathrm{F}$ & Sig. & Partial eta squared \\
\hline Source expertise & .07 & 1 & .07 & .10 & .75 & .00 \\
\hline Message accuracy & 87.01 & 1 & 87.01 & 128.28 & .00 & .18 \\
\hline Source expertise & 1.92 & 1 & 1.92 & 2.83 & .09 & .01 \\
\hline X Message accuracy & & & & & & \\
\hline Error & 387.27 & 571 & .68 & & & \\
\hline Total & 10039.34 & 575 & & & & \\
\hline
\end{tabular}

$\mathrm{R}^{2} \frac{1}{4} .19$

Table 3

Three-way ANOVA for web site credibility moderated by knowledge level.

\begin{tabular}{|c|c|c|c|c|c|c|}
\hline & Type III sum of squares & $\mathrm{df}$ & Mean square & $\mathrm{F}$ & Sig. & Partial eta squared \\
\hline Source expertise & .00 & 1 & .001 & .001 & .97 & .00 \\
\hline Message accuracy & 65.18 & 1 & 65.18 & 96.65 & .00 & .15 \\
\hline Knowledge level & .52 & 1 & .52 & .77 & .38 & .00 \\
\hline Source expertise & 3.55 & 1 & 3.55 & 5.26 & .02 & .01 \\
\hline $\begin{array}{l}\text { X Message accuracy } \\
\text { Source expertise }\end{array}$ & .40 & 1 & .40 & .59 & .44 & .00 \\
\hline $\begin{array}{l}\text { X Knowledge level } \\
\text { Message accuracy }\end{array}$ & .84 & 1 & .84 & 1.24 & .27 & .00 \\
\hline $\begin{array}{l}\text { X Knowledge level } \\
\text { Source expertise } \\
\text { X Message accuracy }\end{array}$ & 2.59 & 1 & 2.59 & 3.84 & .05 & .01 \\
\hline $\begin{array}{l}\text { X Knowledge level } \\
\text { Error }\end{array}$ & 382.36 & 567 & .67 & & & \\
\hline Total & 10039.34 & 575 & & & & \\
\hline
\end{tabular}

$\mathrm{R}^{2} 1 / 4.20$

Table 4

Three-way ANOVA for web site credibility moderated by issue involvement

\begin{tabular}{|c|c|c|c|c|c|c|}
\hline & Type III sum of squares & df & Mean square & $\mathrm{F}$ & Sig. & Partial eta squared \\
\hline Source expertise & .25 & 1 & .25 & .37 & .54 & .00 \\
\hline Message accuracy & 85.26 & 1 & 85.26 & 128.03 & .00 & .18 \\
\hline Issue involvement & 3.97 & 1 & 3.97 & 5.97 & .02 & .01 \\
\hline Source expertise & 1.39 & 1 & 1.39 & 2.09 & .15 & .00 \\
\hline $\begin{array}{l}\text { X Message accuracy } \\
\text { Source expertise } \\
\text { X Issue involvement }\end{array}$ & .01 & 1 & .01 & .02 & .89 & .00 \\
\hline Message accuracy & 4.34 & 1 & 4.34 & 6.51 & .01 & .01 \\
\hline $\begin{array}{l}\text { X Issue involvement } \\
\text { Source expertise } \\
\text { X Message accuracy } \\
\text { X Issue involvement }\end{array}$ & .22 & 1 & .22 & .32 & .57 & .00 \\
\hline Error & 377.60 & 567 & .67 & & & \\
\hline Total & 10039.34 & 575 & & & & \\
\hline
\end{tabular}

$\mathrm{R}^{2} 1 / 4.21$

These findings clearly demonstrate that expertise induced a cueing effect, while message accuracy required participants to elaborate on the message, hence undermining the effect of the source as a heuristic cue. Additionally, the significant interaction between message accuracy and issue involvement reinforced the idea that systematic processing is driven by message accuracy. Thus, as Reinhard and Sporer's (2010) study suggested, message accuracy is not a heuristic cue in information processing for diet-nutrition information online, but source expertise is.

The findings from the present study provide clear evidence to reconcile conflicting results (e.g., Levine \& 
McCornack, 2001; Reinhard \& Sporer, 2010) regarding the impact of content accuracy on cognitive information processing paths. From a theoretical perspective, the present study attempted to explore the moderating factors influencing perceived credibility of online diet and nutrition information. Few studies have examined the factors moderating perceived credibility of online health information, especially regarding the specific topic of diet and nutrition information and using the theoretical grounding of dualprocessing models. The present study revealed that a reader's prior knowledge about a health topic, as well as his/her involvement with it, were more likely to moderate the effects of message accuracy than the cue effect of the information source on perceived web site credibility.

Another interesting finding from the current study is that the expertise cue - which is one of the most wellknown heuristic cues - yielded no significant main effects. Most of the previous literature suggests that people are highly susceptible to what experts say about a health topic (Berlo, Lemert, \& Mertz, 1970). Therefore, knowing that information came from the CDC e one of the most authoritative sources of health information for Americans e might have had a significant effect on users' credibility assessments. One possible explanation for this finding is that, for information about whole grain food, readers might not require the strong credentials of an authoritative web sitelike the CDC because information about the benefits of whole grain products are quite familiar to most people.

However, it must be noted that message accuracy exerted a stronger effect than the source expertise cue, despite the different patterns observed between the groups with low and high levels of knowledge. Thus, when it comes to a well-known health topic and information processing, accurate descriptions about the topic should be a priority in order to gain credibility among online information seekers. When people hold a confident level of processing information regarding their familiarity with the topic or knowledge of it (i.e., sufficiency threshold), heuristic processing is unlikely, but instead, systematic processing is likely to occur (Eagly \& Chaiken, 1993). Consistently, the findings of this study suggest when people are confident in their knowledge of a topic, they process information systematically, but when their knowledge levels are low, they rely on heuristic cues. If the health topic was more serious (e.g. cancer information) or less familiar (e.g. emerging diseases) than the one used in the current study, then the study might have produced different results.

In addition to these important theoretical implications, the study also provides valuable practical insights for presenting online diet and nutrition information. Understanding the factors influencing audiences' ratings of online diet and nutrition information will help online health content providers to learn more effective ways to create online health messages. This is especially important because well-made web sites can provide useful and accurate health information, such as how to prevent obesity and diabetes caused by poor dietary habits. Because the number of people who pay attention to online health information has increased, especially through social media (PriceWaterhouse Coopers, 2012), online content providers should carefully consider designing health-related messages. In addition, the fact that source expertise had produced no main effects on perceived website credibility suggests that audiences are likely to perceive websites as credible so long as they believe the information provided to be accurate $\mathrm{e}$ even when they do not perceive the source to be an expert. In this sense, online health content providers should be very careful to present accurate health information, regardless of their Web sites' reputation. Apart from the main effects of message accuracy, our interaction effects findings suggest that source expertise cues enhanced perceived web site credibility for those with low prior knowledge about the health topic (i.e., whole food intake) when the message is inaccurate. Specifically, if users do not have enough knowledge about the particular issue presented on the web site, they are more likely to rely on the source expert cue. In the same vein, if information on the web site is inaccurate or controversial, the role of source expert cue will be highlighted. Therefore, health information web sites should be designed to take into account the likely knowledge levels of the target user groups and the core topics to be addressed. 
Study limitations must be noted, however. First, because the present study used a specific diet and nutrition topic (i.e., whole grain food intake), source expertise, message accuracy, knowledge level, and issue involvement might not have the same effects on perceived credibility for all online diet and nutrition information. Therefore, future studies should replicate this research with other diet and nutrition topics to verify the effects. Moreover, other health topics (not limited to diet and nutrition) and topics in other contexts (e.g., science, life, entertainment, etc.) need to be further explored to allow more generalizable conclusions about how individuals process online information. Second, the present study examined the moderating effects of knowledge level and issue involvement. However, it did not control for other variables that also might have affected the relationships among the main variables tested in the study. For example, health information-seeking tends to be affected by users' health status, physical condition, and general health concerns (Houston \& Alison, 2002; Powell, Inglis, Ronnie, \& Large, 2011). In this sense, further studies should consider diverse variables that can affect perceptions, attitudes, and behaviors related to users' health information searches. Third, it should be noted that all interaction effects in the results had fairly small effect sizes (partial $\eta^{2}=.01$ ), even when they were significant. This may be attributed to the very weak effect of source expertise on web site credibility, which in turn truncated effect size estimates in the interaction effects. Despite the small effect size, we revealed meaningful interaction patterns on multiple conditions (i.e., message accuracy, source expertise, issue involvement, and prior knowledge). In order to clarify these interaction effects, further investigations are needed using other source expertise cues. Lastly, the online experimental environment could have influenced the findings because researchers could not control potential distractions the participants had during the selfinstructed online experiment. Thus, caution should be exercised in generalizing from the present study's findings.

All in all, this study represents a step toward understanding how people perceive online diet and nutrition information and offers a valuable contribution to the development of online health communication practices.

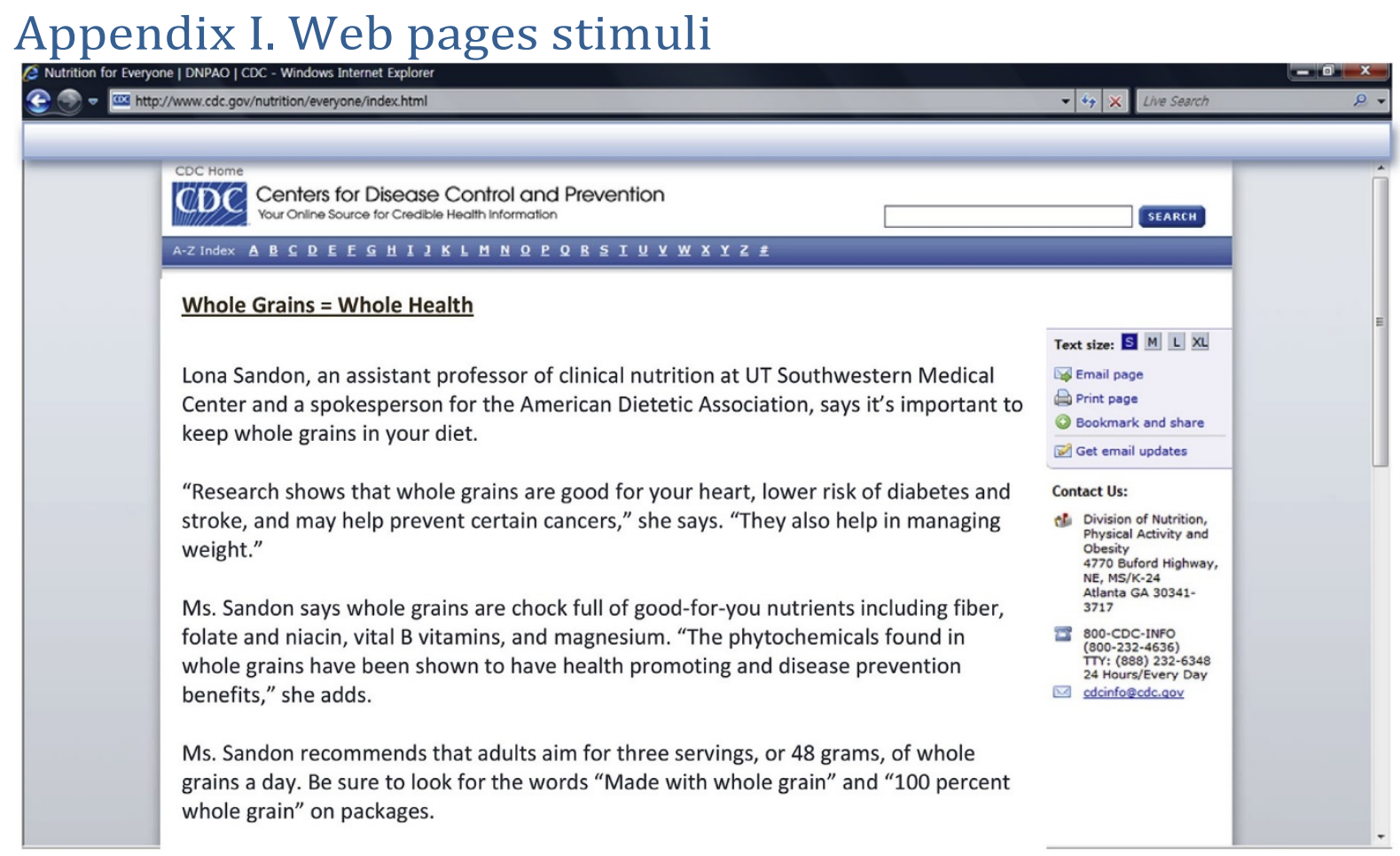

Stimulus 1. High level of source expertise

(CDC) X Accurate message 


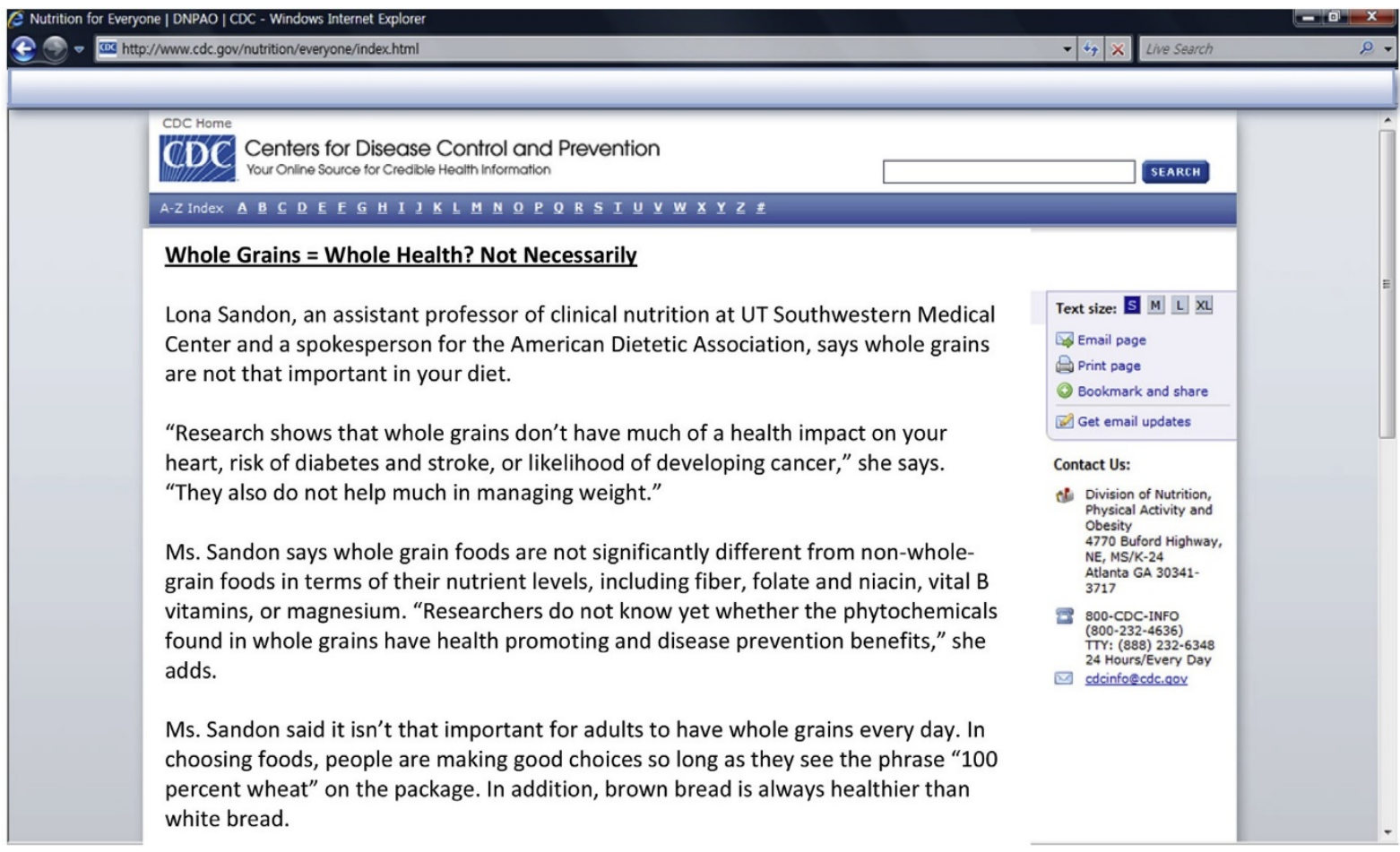

Stimulus 2. High level of source expertise

(CDC) X Inaccurate message.

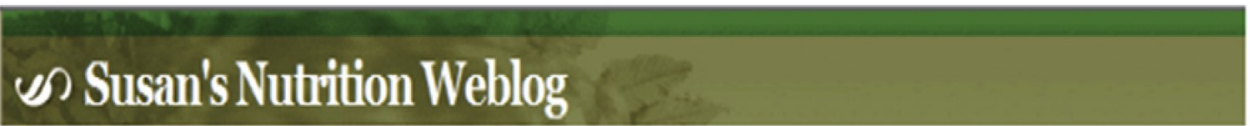

Whole Grains $=$ Whole Health

Lona Sandon, an assistant professor of clinical nutrition at UT Southwestern Medical Center and a spokesperson for the American Dietetic Association, says it's important to keep whole grains in your diet.

"Research shows that whole grains are good for your heart, lower risk of diabetes and stroke, and may help prevent certain cancers," she says. "They also help in managing weight."

Ms. Sandon says whole grains are chock full of good-for-you nutrients including fiber, folate and niacin, vital B vitamins, and magnesium. "The phytochemicals found in whole grains have been shown to have health promoting and disease prevention benefits," she adds.

Ms. Sandon recommends that adults aim for three servings, or 48 grams, of whole grains a day. Be sure to look for the words "Made with whole grain" and "100 percent whole grain" on packages.

Stimulus 3. Low level of source expertise (Personal blog) X Accurate message. 


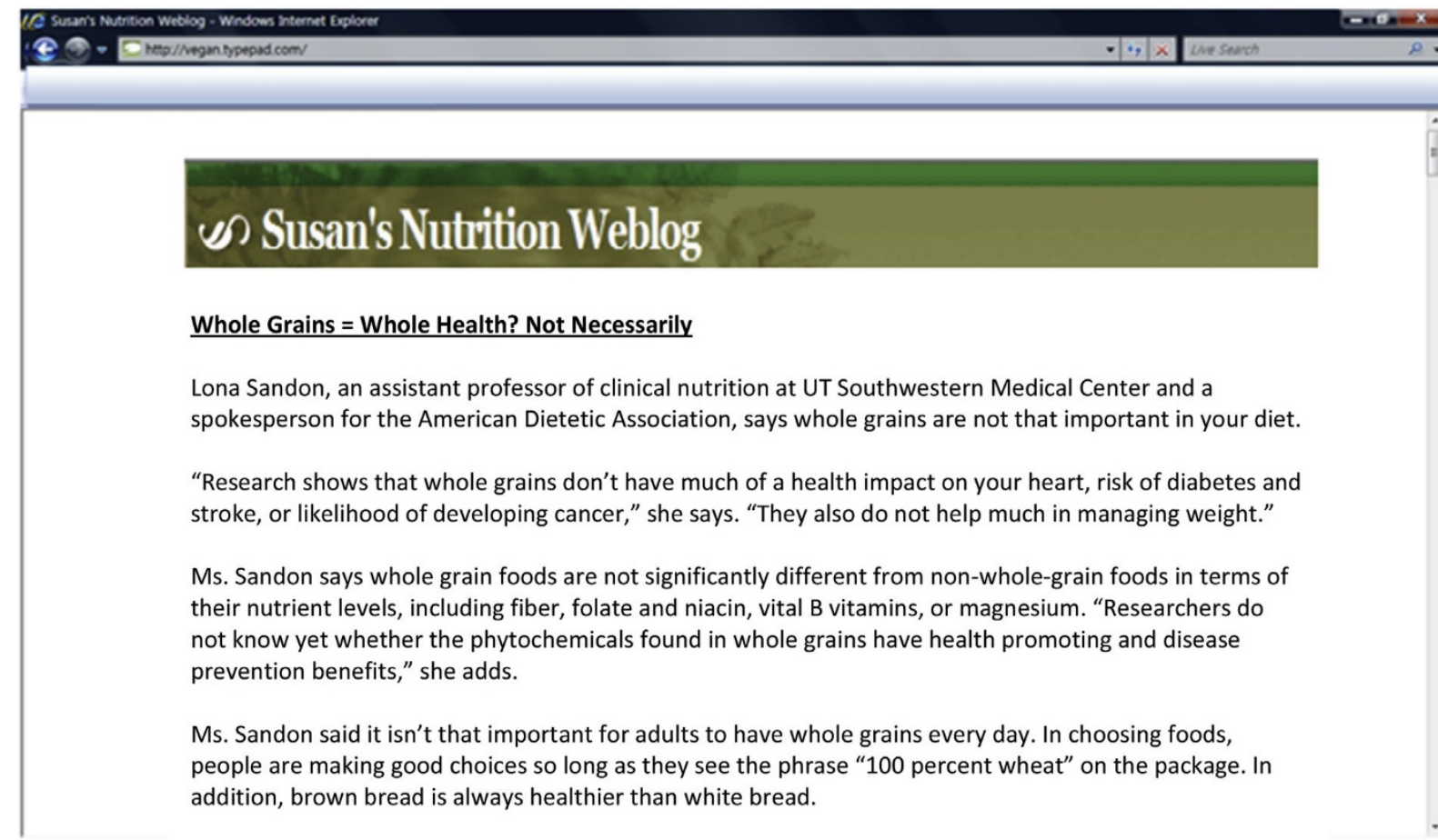

Stimulus 4. Low level of source expertise (Personal blog) X

Inaccurate message.

\section{References}

Ayoob, K., Duyff, R. L., \& Quagliani, D. (2002). Position of the American dietetic association: food and nutrition misinformation. Journal of the American Dietetic Association, 102(2), 260-266.

Baker, L., Wagner, T. H., Singer, S., \& Bundorf, M. K. (2003). Use of the internet and e-mail for health care information: results from a national survey. Journal of the American Medical Association, 289(18), 2400-2406.

Bass, S. B., Ruzek, S. B., Gordon, T. F., Fleisher, L., McKeown-Conn, N., \& Moore, D. (2006). Relationship of internet health information use with patient behavior and self-efficacy: experiences of newly diagnosed cancer patients who contact the National Cancer Institute's cancer information service. Journal of Health Communication, 11(2), 219-236.

Berlo, D. K., Lemert, J. B., \& Mertz, R. J. (1970). Dimensions for evaluating the acceptability of message sources. Public Opinion Quarterly, 33(4), 563-576.

Bucy, E. P. (2003). Media credibility reconsidered: synergy effects between on-air and online news. Journalism \& Mass Communication Quarterly, 80(2), 247-264.

Buntin, M. B., Burke, M. F., Hoaglin, M. C., \& Blumenthal, D. (2011). The benefits of health information technology: a review of the recent literature shows predominantly positive results. Health Affairs, 30(3), 464-471.

Centers for Disease Control. (2011). The obesity epidemic. Retrieved online from http://www.cdc.gov/cdetv/ObesityEpidemic/.

Chaiken, S. (1980). Heuristic versus systematic information processing and the use of source versus message cues in persuasion. Journal of Personality and Social Psychology, 89(5), 752-766.

Chaiken, S., Liberman, A., \& Eagly, A. H. (1989). Heuristic and systematic information processing within and beyond the persuasion context. In J. S. Uleman, \& J. A. Bargh (Eds.), Unintended thought (pp. 212- 
252). New York: Guilford Press.

Charlton, K. E., Brewitt, P., \& Bourne, L. T. (2004). Sources and credibility of nutrition information among black urban South African women, with a focus on messages related to obesity. Public Health Nutrition, 7(06), 801-811.

Chen, S., \& Chaiken, S. (1999). The Heuristic-Systematic Model in its broader context. In S. Chaiken, \& Y. Trope (eds.), Dual-process theories in social psychology (pp. 73-96). New York, NY: The Guilford Press.

Colleran, H. L., \& Lovelady, C. A. (2012). Use of MyPyramid Menu Planner for Moms in a weightloss intervention during lactation. Journal of the Academy of Nutrition and Dietetics, 112(4), 553558.

Crow, J. M. (2012). Obesity: insensitive issue. Nature, 486(7403), S12-S13.

Eagly, A., \& Chaiken, S. (1993). The psychology of attitude. Fort Worth, TX: Harcourt, Brace, \& Janovich.

Eastin, M.S., (2001). Credibility assessments of online health information: the effects of source expertise and knowledge of content. Journal of Computer-Mediated Communication, 6(4), 0.

Fahy, E., Hardikar, R., Fox, A., \& Mackay, S. (2014). Quality of patient health information on the internet: reviewing a complex and evolving landscape. The Australasian medical journal, 7(1), 24.

Flanagin, A. J., \& Metzger, M. J. (2003). The perceived credibility of personal web page information as influenced by the sex of the source. Computers in Human Behavior, 19(6), 683-701.

Fox, S. (2006). Online health search 2006 Retrieved online from http://www. pewinternet.org/2006/10/29/online-health-search-2006/.

Fox, S., \& Duggan, M. (2013). Health online 2013. Retrieved online from http://www. pewinternet.org/2013/01/15/health-online-2013/.

Fox, S., \& Jones, S. (2009). The social life of health information (online health information use). Retrieved online from http://www.pewinternet.org/Reports/2009/8-The-Social-Life-of-HealthInformation.aspx.

Gaziano, C., \& McGrath, K. (1986). Measuring the concept of credibility. Journalism Quarterly, 63(3), 451-462.

Goldberg, J. P., \& Sliwa, S. A. (2011). Communicating actionable nutrition messages: challenges and opportunities. Proceedings of the Nutrition Society, 70(01), 26-37.

Grunert, K. G., Wills, J., Fernandez-Celemin, L., Lah-teenmaki, L., Scholderer, J., \& Storcksdieck genannt Bonsmann, S. (2012). Socio-demographic and attitudinal determinants of nutrition knowledge of food shoppers in six European countries. Food Quality and Preference, 26, 166177.

Hallahan, K. (2000). Enhancing the motivation, ability and opportunity to process public relations messages. Public Relations Review, 26(4), 463-480.

Harris, P. R., Sillence, E., \& Briggs, P. (2009). The effect of credibility-related design cues on responses to a web-based message about the breast cancer risks from alcohol: randomized controlled trial. Journal of Medical Internet Research, 11(3), e37.

Hong, T. (2006). The influence of structural and message features on web site credibility. Journal of the American Society for Information Science and Technology, 57(1), 114-127.

Houston, T. K., \& Alison, J. J. (2002). Users of internet health information: differences by health status. Journal of Medical Internet Research, 4(2), e7.

Hovland, C. I., \& Weiss, W. (1951). The influence of source credibility on communication effectiveness. Public Opinion Quarterly, 15(4), 635-650.

$\mathrm{Hu}$, Y., \& Sundar, S. S. (2010). Effects of online health sources on credibility and behavioral intentions. Communication Research, 37(1), 105-132.

Jacobs, D. R., Pereira, M., Slavin, M. J., \& Marquart, L. (2000). Defining the impact of wholegrain intake on chronic disease. Cereal Foods World, 45(2), 51-53. 
Kerstetter, D., \& Cho, M. (2004). Prior knowledge, credibility, and information search. Annals of Tourism Research, 31(4), 961-985.

Kruglanski, A. W., Chen, X., Pierro, A., Mannetti, L., Erb, H.-P., \& Spiegel, S. (2006). Persuasion according to the unimodel: implications for cancer communication. Journal of Communication, 56(S1), S105-S122.

Kunst, H., Groot, D., Latthe, P. M., Latthe, M., \& Khan, K. S. (2002). Accuracy of information on apparently credible websites: survey of five common health topics. British Medical Journal, 324(7337), 581582.

Lee, J. Y., \& Sundar, S. S. (2013). To tweet or to retweet? That is the question for health professionals on Twitter. Health Communication, 28(5), 509-524.

Levine, T. R., \& McCornack, S. A. (2001). Behavioral adaptation, confidence, and heuristic-based explanations of the probing effect. Human Communication Research, 27, 471-502.

Lim, Y. S., \& Van Der Heide, B. (2015). Evaluating the wisdom of strangers: the perceived credibility of online consumer reviews on yelp. Journal of Computer-Mediated Communication, 20(1), 67-82.

Malik, V. S., Willett, W. C., \& Hu, F. B. (2013). Global obesity: trends, risk factors and policy implications. Nature Reviews Endocrinology, 9(1), 13-27.

McConnon, A., Kirk, S. F., \& Ransley, J. K. (2009). Process evaluation of an internet-based resource for weight control: use and views of an obese sample. Journal of Nutrition Education and Behavior, 41(4), 261-267.

McIntosh, G. H., Noakes, M., Royle, P. J., \& Foster, P. R. (2003). Whole-grain rye and wheat foods and markers of bowel health in overweight middle-aged men. The American Journal of Clinical Nutrition, 77, 967-974.

Metzger, M. J. (2007). Making sense of credibility on the web: models for evaluating online information and recommendations for future research. Journal of the American Society for Information Science and Technology, 58, 2078-2091.

Modave, F., Shokar, N. K., Peñaranda, E., \& Nguyen, N. (2014). Analysis of the accuracy of weight loss information search engine results on the internet. American Journal of Public Health, 104(10), 1971-1978.

Neuhauser, L., \& Kreps, G. L. (2003). Rethinking communication in the E-health era. Journal of Health Psychology, 8(1), 7-23.

Petty, R. E., \& Cacioppo, J. T. (1984). The effects of involvement on responses to argument quantity and quality: central and peripheral routes to persuasion. Journal of Personality and Social Psychology, 46, 69-81.

Petty, R. E., \& Cacioppo, J. T. (1986). Communication and persuasion: Central and peripheral routes to attitude change. New York: SpringerVerlag.

Petty, R. E., \& Cacioppo, J. T. (1990). Involvement and persuasion: tradition versus integration. Psychological Bulletin, 107(3), 367-374.

Petty, R. E., Cacioppo, J. T., \& Goldman, R. (1981). Personal involvement as a predictor of argument-based persuasion. Journal of Personality and Social Psychology, 41, 847-855.

Petty, R. E., \& Wegener, D. T. (1999). The elaboration likelihood model: current status and controversies. In S. Chaiken, \& Y. Trope (Eds.), Dual-process theories in social psychology (pp. 41e72). New York, NY: The Guilford Press.

Powell, J., Inglis, N., Ronnie, J., \& Large, S. (2011). The characteristics and motivations of online health information seekers: Cross-sectional survey and qualitative interview study. Journal of Medical Internet Research, 13(1), e20.

PriceWaterhouse Coopers. (2012). Social media "likes" healthcare: From marketing to social business. Retrieved from www.pwc.com/us/en/health-industries/publications/health-care-socialmedia.jhtml. 
Reinhard, M. A., \& Sporer, S. L. (2010). Content versus source cue information as a basic for credibility judgments: the impact of task involvement. Social Psychology, 41, 93-104.

Roebroek, S. J., Brouwer, W., Lindeboom, D., Oenema, A., \& Burdorf, A. (2010). Demographic, behavioral, and psychosocial correlates of using the website component of a worksite physical activity and healthy nutrition promotion program: a longitudinal study. Journal of Medical Internet Research, 12(3), e44.

Roebroek, S. J., Lindeboom, D. E., \& Burdorf, A. (2012). Initial and sustained participation in an internetdelivered long-term worksite health promotion program on physical activity and nutrition. Journal of Medical Internet Research, 14(2), e43.

Rutsaert, P., Regan, A., Pieniak, Z., McConnon, A., Moss, A., Wall, P., et al. (2013). The use of social media in food risk and benefit communication. Trends in Food Science \& Technology, 30(1), 8491.

Spiteri Cornish, L., \& Moraes, C. (2015). The impact of consumer confusion on nutrition literacy and subsequent dietary behavior. Psychology \& Marketing, 32(5), 558-574.

Street, R. L., Jr., \& Piziak, V. K. (2001). Improving diabetes care with telecomputing technology. In R. E. Rice, \& J. E. Katz (eds.), The Internet and health communication (pp. 287-327). Thousand Oaks, CA: Sage.

Theodosiou, L., \& Green, J. (2003). Emerging challenges in using health information from the internet. Advances in Psychiatric Treatment, 9(5), 387-396.

Thomm, E., \& Bromme, R. (2012). "It should at least seem scientific!" Textual features of "scientificness" and their impact on lay assessments of online information. Science Education, 96(2), 187-211.

Thorndike, A. N., Sonnenberg, L., Healey, E., Myint-U, K., Kvedar, J. C., \& Regan, S. (2012). Prevention of weight gain following a worksite nutrition and exercise program: a randomized controlled trial. American Journal of Preventive Medicine, 43(1), 27-33.

Tsai, C. C., Tsai, S. H., Zeng-Treitler, Q., \& Liang, B. A. (2007). Patient-centered consumer health social network websites: a pilot study of quality of user-generated health information. Proceedings of the Annual Symposium of the American Medical Informatics Association, 1137.

Tudoran, A., Olsen, S. O., \& Dopico, D. C. (2009). The effect of health benefit information on consumers health value, attitudes and intentions. Appetite, 52(3), 568-579.

Vance, K., Howe, W., \& Dellavalle, R. P. (2009). Social internet sites as a source of public health information. Dermatologic Clinics, 27(2), 133-136.

Walther, J. B., Wang, Z., \& Loh, T. (2004). The effect of top-level domains and advertisements on health web site credibility. Journal of Medical Internet Research., 6(3), e24.

Wang, L., Wang, J., Wang, M., Li, Y., Liang, Y., \& Xu, D. (2012). Using Internet search engines to obtain medical information: a comparative study. Journal of Medical Internet Research, 14(3), e74.

Wei, Y., Rickard, M., \& Brown, C. (2015). Effects of consumer weight level and advertising appeals on consumer attitude toward food and advertisements. Journal of Food Products Marketing, 21(4), $1-16$.

Wilson, B. J. (2007). Designing media messages about health and nutrition: what strategies are most effective? Journal of Nutrition Education and Behavior, 39(2), S13-S19. 